\title{
Hastane kapasitesini aşmayacak şekilde Covid-19 yayılımının geri adımlamalı kontrolü
}

\author{
Back-stepping control of Covid-19 spread not to exceed hospital capacity
}

\author{
Hacı Mehmet GÜZEY*1,a \\ ${ }^{\text {I} E r z u r u m ~ T e k n i k ~ U ̈ n i v e r s i t e s i, ~ M u ̈ h e n d i s l i k ~ v e ~ M i m a r l ı k ~ F a k u ̈ l t e s i, ~ E l e k t r i k-E l e k t r o n i k ~ M u ̈ h e n d i s l i g ̆ i ~ B o ̈ l u ̈ m u ̈, ~ 25050, ~ E r z u r u m ~}$
}

• Geliş tarihi / Received: 15.06.2020 • Düzeltilerek geliş tarihi / Received in revised form: 06.03.2021 • Kabul tarihi / Accepted: 22.03.2021

\section{$\ddot{O} z$}

COVID-19 salgınının, İtalya örneğine dayanan sosyal uzaklaştırma önlemleri ile geri adımlamalı kontrol metodu kullanılarak hastanede yatması gereken hasta sayısının, mevcut yatak kapasitesini geçmeyecek şekilde kontrolü ele alınmıştır. Sosyal mesafe önlemleri, sokağa çıkma yasağı gibi önlemler ile devletler ve yerel idareler salgının yayılmasını önlemek istemektedir. Salgının tamamen yayılmasını önlemek ancak mutlak bir tecrit ile olabilecekken, bu çözüm sosyal hayatın ve ekonominin aşırı derecede olumsuz etkilenmesine sebep verecektir. Bu nedenle, her bir ülke/şehir, en azından kendi yatak kapasitesini aşmayacak şekilde salgını kontrol altına almak isteyecektir. Bu makaledeki bulgular, şehir yöneticilerine veyahut genel idarecilere, salgını yönetmek için referans teşkil edecektir. İnsanların salgınla olan alakasına göre, bu makalede toplum sekiz bölüme ayrılmıştır. Bunlarda bir gurup ise tedavisi zaruri olmuş guruptur. Geri adımlamalı denetleyici vasıtasıyla, hastaneye yatması gereken hasta sayısının, mevcut yatak kapasitesinden az değerde tutulduğu ispatlanmıştır. Benzetim sonuçları da iddia edilen kontrolcünün sorunsuz çalıştığını göstermektedir.

Anahtar kelimeler: Covid-19, Geri adımlamalı kontrol, Yayılım kontrolü

\begin{abstract}
In this paper, controlling the number of patients who are required to stay in hospitals due to covid-19 through backstepping controller is considered by using data from Italy. States and local administrations want to prevent the spread of the outbreak, with measures such as social distance measures, curfews. Even though the absolute control of the pandemic can be reached through absolute isolation, this solution will cause excessive negative effects on social life and economy. Therefore, each country/city would like to control the outbreak, at least not exceeding its bed capacity. The results of this article has potential of serving as a reference for city administrators or general administrators to manage the outbreak. Based on the current health condition of the people due to the epidemic, society is divided into eight sections in this article. One of these eight population groups is the ones whose hospital treatment is mandatory. With the back-stepping controller, it is proven that the number of patients who need to be hospitalized can be kept below the current bed capacity. Simulation results also show that the proposed controller is effectively controls the patients those need to be hospitalized.
\end{abstract}

Keywords: Covid-19, Back-stepping control, Spread control

*a Hacı Mehmet Güzey; mehmet.guzey@erzurum.edu.tr, Tel: (0546) 6361766, orcid.org/0000-0002-2215-9536 


\section{Giriş}

Salgın yayılımını kontrol etmek için, özellikle virüs ile alakalı çok az bilgi varsa ve henüz aşı mevcut değilse, devletin ve/veya yerel yönetimlerin sosyal mesafeyi koruyucu tedbirler alması gerekir. Sosyal mesafe kuralları, sokağa çıkma yasağı, maske kullanımı ve hijyen gibi tedbirlerin, virüsün yayılımı ciddi şekilde azalttığ1 daha önceki çalışmalarda gösterilmiştir (Maharaj vd., 2012; Kissler vd., 2020; Majer vd., 2020). Bununla birlikte, sokağa çıkma yasağı gibi katı sosyal mesafe tedbirlerinin doğal olarak ciddi ekonomik ve psikolojik hasarlara yol açtığı da yadsınamaz bir gerçektir. Bu nedenle, İngiltere tarafından başlangıçta tercih edilmiş ve kısa süre sonunda vazgeçilmiş, ağır ölüm ve vaka oranları ile sonuçlanacağı bariz olan sürü bağışıklığ yöntemini kullanmak ne kadar makul değilse, tersi durum olan katı sosyal tecrit de aynı şekilde tercih edilecek bir yol değildir. Bu bağlamda, salgının yayılımının modellenmesi ve bu model üzerinden politika geliştirilerek, salgını kontrol altında tutma ihtiyacı ortaya çıkmıştır.

COVID-19 salgınının yayılımını modellemek için çok sayıda yaklaşım geliştirilmiştir ve benzetim çalışmaları ile, farklı politikaların yayılımın üzerinde etkileri incelenmiştir. En yaygın olarak kullanılan modelleme yaklaşımı SIR modelidir (Dehning vd., 2020; Barbarossa vd., 2020; German vd., 2020). Bu modelde, toplum üç temel guruba ayrılır: S (hastalığa duyarlı insanlar), I (hastalık bulaşmış olan insanlar), R (Hastalık bulaşmış ve sonrasında tamamen iyileşmiş insanlar). Son günlerde, etkili bir kontrol stratejisi planlamaya yardımcı olmak için salgının gidişatını tahmin eden, SIR modelinden daha detaylı olan SIDARTHE modeli (Giordano vd., 2020)'de geliştirilmiştir. Model, sekiz enfeksiyon aşamalarına göre bireyleri sekiz bölümde inceler: hastalık bulaşmamış bireyler (S), hastalık bulaşmış ve tespit edilmemiş bireyler (I), hastalık belirtisi göstermeyen, hastalık tespit edilmiş bireyler (D), hastalık belirtisi gösterdiği halde tespit edilemeyen bireyler (A), hastalık belirtisi gösterip, tespit edilen bireyler (R), şu anda tedavi gören bireyler (T), hastalık bulaşmış ve sonrasında hastalıktan tamamen kurtulmuş bireyler $(\mathrm{H})$ ve hastalık sonucu hayatını kaybetmiş bireyler (E). SIDARTHE modeli, hastalık bulaşan bireylerin teşhis edilip edilmediğine ve belirtilerinin şiddetine bağlı olarak ayrım yapar. Teşhis edilen ve teşhis edilmeyen bireyler arasındaki ayrım önemlidir, çünkü ilki toplumdan izole edilir ve dolayısıyla salgını yayma olasılığı daha düşüktür. $\mathrm{Bu}$ tanımlama aynı zamanda vaka ölüm oranı ve salgın yayılımının yanlış algısını açıklamaya da yardımcı olur.

Salgınların matematiksel modellenmesi literatürde çokça çalışılmış bir konudur. Güncel olarak, COVID-19 yay1lımına kontrol teorisini uygulamak için çok sayıda yaklaşım olmuştur. (Casella, 2020) 'de yazar sistem modelindeki belirsizlikler ve gecikmeler durumunda kontrol algoritmas1 geliştirmiştir. (Bin vd., 2020; Tsay vd., 2020) 'da sosyal mesafeyi sağlamak için en uygun bang-bang kontrolcü geliştirmiştir. Bunun yanında, (Lauro vd., 2021) salgin yayılımını engellemede en uygun kontrol tekniğini kullanmışlardır. (Casella, 2021)'de ise COVID-19 salginlarının, swab testi sonuçlarına, aktif vakalara ve toplam vakalara ilişkin günlük raporlara dayanarak halk sağlığı önlemleri hakkında kararlar alan yetkililer tarafından kontrol edilip edilemeyeceğini ve ne ölçüde kontrol edilebileceğini araştırmaktadır. Bahsi geçen tüm çalışmalar, Covid-19 salgınının yayılımını kontrol ederken referans olarak hastalık bulaşmış bireyleri dikkate almıştır. Bu makalede ise, daha önceki çalışmalarda (Güzey vd., 2016, 2017, 2019) insansız araçların kontrolü için sıkça kullanılan geri adımlamalı kontrol yaklaşımı kullanılarak, hastanede yatması gereken insan sayısını (T), hastane kapasitesini geçmeyecek şekilde kontrol altında tutacak kontrolcüler geliştirilmiştir. Geri adımlamalı denetleyici kullanılmasinın sebebi ise, kontrol parametrelerinin hastanede yatmas1 gereken hastaların (T) dinamik denklemlerinde olmaması ve diğer durumların hayali kontrolcü olarak kullanılması gerektiğidir.

\section{Materyal ve yöntem}

$\mathrm{Bu}$ bölümde, sonraki bölümde tasarlayacağımız kontrol algoritmamız için kullandığımız COVID19 salgınının modeli verilmektedir (Giordano vd., 2020).

$$
\begin{aligned}
& \dot{S}(t)=-S(t)(\alpha I(t)+\beta D(t)+\gamma A(t)+\delta R(t)) \\
& \dot{I}(t)=S(t)(\alpha I(t)+\beta D(t)+\gamma A(t)+\delta R(t))-(\varepsilon+\zeta+\lambda) I(t) \\
& \dot{D}(t)=\varepsilon I(t)-(\eta+\rho) D(t)
\end{aligned}
$$




$$
\begin{aligned}
& \dot{A}(t)=\zeta I(t)-(\theta+\mu+\kappa) A(t) \\
& \dot{R}(t)=\eta D(t)+\theta A(t)-(v+\xi) R(t) \\
& \dot{T}(t)=\mu A(t)+v R(t)-(\sigma+\tau) T(t) \\
& \dot{H}(t)=\lambda I(t)+\rho D(t)+\kappa A(t)+\xi R(t)+\sigma T(t) \\
& \dot{E}(t)=\tau T(t)
\end{aligned}
$$

Yukarıdaki denklemlerde, (1)-(8), büyük harfler, Şekil 1'de de gösterildiği üzere, salgınla olan münasebetine göre toplum içerisindeki gurupların toplam nüfusa oranını temsil etmektedir. Model

$$
S(t)+I(t)+D(t)+A(t)+R(t)+T(t)+H(t)+E(t)=1
$$

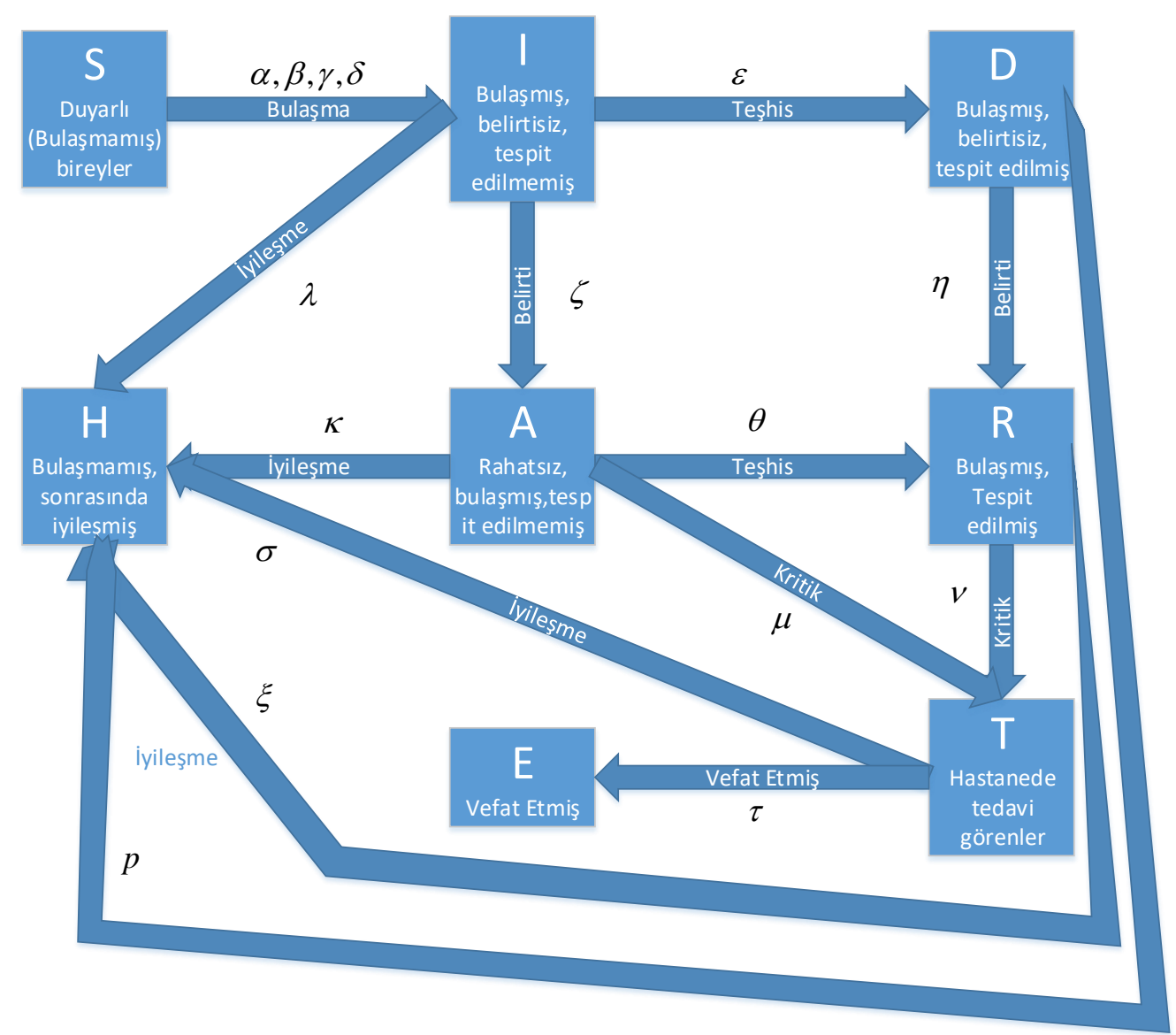

Şekil 1. SIDARTHE matematiksel modelinde salgının farklı aşamaları arasındaki etkileşimleri temsil eden grafik şeması.

Eşitliklerde geçen, küçük harflerle belirtilen Yunan alfabesi karakterleri ise aşağıda tanımlanmıştır: $\alpha, \beta, \gamma, \delta: \quad$ Hastalık bulaşmamış bireyler gurubundan (S), sirasiyla, I, D, A ve R guruplarina geçişin hızını tanımlamaktadır. Bu parametreler devlet politikası sonucunda, okulların kapatılması, uzaktan çalışma, sokağa çıkma yasağ mesafe önlemleri ile azaltılabilir.

$\varepsilon, \theta:$ Strasiyla, belirti gösteren ve belirti göstermeyen hastaların tespit edilme hızlarını ifade etmektedir.

$\zeta, \eta$ : Sirasıla tespit edilen ve edilmeyen bireylerin belirti gösterme hızlarını vermektedir. 
$\mu, v$ : Sırasılyla tespit edilmiş ve tespit edilmemiş bireylerin hastanede yatma gereksinimi hızlarını belirlemektedir.

$\tau$ : Hayati tehlikesi olan hastalar içerisinde ölüm oranını ifade eder. Bu oran, tedavi yöntemlerinin iyileştirilmesi ile azaltılabilir.

$\lambda, \kappa, \xi, \rho, \sigma$ : Sirasiyla, I, A, R, D ve T gurubundaki bireylerin iyileşerek $\mathrm{H}$ gurubuna geçme hızlarını ifade eder.

Tehdit altındaki bireyler için iyileşme oranı $\sigma(T)$ , ölüm oranı ise $\tau(T)$ 'dir ve her ikisi de tedavi gören hasta oranı, T'ye bağlıdır. Buradan da anlaşılacağı üzere, Hastanede yatan bireylerin azalması hem yatak kapasitesinin aşılmamasını sağlayacağı gibi, hem de ölüm oranlarını düşürecektir.

Sonraki bölümde, tasarlamış olduğumuz geri adımlamalı kontrolcü verilmiştir.

\section{Geri adımlamalı kontrolcü tasarımı}

Bu bölümde, dinamik denklemleri (1)-(8) verilen salgın modelinde, hastanede tedavi görmesi gereken hasta sayısının, $T$, hasta yatak kapasitesini, $T^{\max }$, aşmaması için kontrolcü tasarlanmaktadır. Kontrol parametreleri olarak, hastalığa duyarlı bireylerin, hastalık bulaşma oranları $\alpha, \beta$ seçilerek, her ikisi için ayrı ayrı kontrolcü tasarlanmaktadır. $\mathrm{Bu}$ vesileyle, idarecilere iki farklı kontrol parametresi seçeneği sunulacak ve sosyal ekonomik olarak daha az maliyetli olanı tercih etme imkânına sahip olacaklard1. Kontrol parametreleri, $\alpha, \beta$, tedavi gören hasta oranının dinamiğinde (6) direk bulunmadığı için, $T$ 'yi kontrol etmek için Lyapunov kararlılık kriteri kullanılarak üç adımda, geri adımlamalı kontrolcü tasarımı gerçekleştirilmektedir.

Birinci adımda, $A$ durumu hayali kontrolcü olarak $T$ nin $T^{\max }{ }_{1}$ geçmemesini sağlayacak şekilde tanımlanır. İkince adımda, $I$ değişkeni, $A$ değişkeninin beklenen sinyali takip etmesi için hayali kontrolcü olarak tanımlanır. Son adımda, $I$ değişkeninin beklenen sinyali takip etmesi için, sirasıyla kontrolcüler, $\alpha, \beta$, tasarlanır.

\subsection{Yatan hasta saylsı, $T$ 'nin kontrolü}

İlk olarak, hastane yatak kapasitesi, $T^{\text {max }}$ olarak tanımlanırsa, azami hastanede yatması muhtemel hasta sayısıyla, o anki hastanede yatması gereken hasta sayısı arasındaki fark
$e_{T}=T-T^{\max }$

olarak tanımlanır. Daha sonra, Lyapunov fonksiyonu (10)'a bağlı olarak

$$
L_{T}=\frac{1}{2} e_{T}^{2}
$$

verilir. (11)'in türevi alınırsa,

$\dot{L}_{T}=e_{T} \dot{e}_{T}=e_{T}\left(\dot{T}-\dot{T}^{\max }\right)$

elde edilir.

Hasta yatak kapasitesi zamanla değişmediği varsayılarak, eşitlik (6), (12)'de yerine yazılarak

$$
\dot{L}_{T}=e_{T}(\mu A(t)+v R(t)-(\sigma+\tau) T(t))
$$

olarak bulunur. Eşitlik (13)'de,

$$
A^{d}(t)=\frac{1}{\mu}\left(-v R(t)+(\sigma+\tau) T(t)-k_{T} e_{T}\right),
$$

$k_{T}>0$ kontrol parametresi olmak üzere hayali kontrolcü olarak seçilir ve (13) 'de $A(t)$ yerine yazılırsa, eşitlik (13)

$\dot{L}_{T}=-k_{T} e_{T}^{2}$

olur. Eşitlik (15)'den $\quad e_{T}$ 'nin, $A(t) \rightarrow A^{d}(t)$, durumunda asimptotik kararlı olduğunu sonucu açıkça görülmektedir. Bir sonraki adımda ise, $I$ parametresi hayali kontrolcü olarak kullanılarak,

$e_{A}=A(t)-A^{d}(t)$

kontrol edilecektir.

\subsection{I hayali kontrolcüsü ile $e_{A}$ 'nin kontrolü}

Bu bölümde, hayali kontrolcü olarak tanımlanan, $A(t)$ 'nin olması gereken değeri, $A^{d}(t)$ takip etmesi için, hastalık bulaşmış birey sayısı, hayali kontrolcü olarak tanımlanacaktır. Bu kapsamda, (16)'ya bağlı Lyapunov fonksiyonu

$L_{A}=\frac{1}{2} e_{A}^{2}$

olarak seçilir ve türevi alınırsa 


$$
\begin{aligned}
& \dot{L}_{A}=e_{A} \dot{e}_{A}=e_{A}\left(\dot{A}-\dot{A}^{d}\right) \\
& \dot{A}^{d}(t)=-v \frac{1}{\mu} \dot{R}(t)+\frac{1}{\mu}(\sigma+\tau) \dot{T}(t)-\frac{1}{\mu} k_{T} \dot{e}_{T}
\end{aligned}
$$
elde edilir. Eşitlik (14)’ün türevi alınır,

(19) ve (4), (18)'de yerine yazılırsa

$\dot{L}_{A}=e_{A}\left(\zeta I(t)-(\theta+\mu+\kappa) A(t)-\left(-v \frac{1}{\mu} \dot{R}(t)+\frac{1}{\mu}(\sigma+\tau) \dot{T}(t)-\frac{1}{\mu} k_{T} \dot{T}\right)\right)$

olarak bulunur. Hayali kontrolcü

$I^{d}(t)=\frac{1}{\zeta}\left((\theta+\mu+\kappa) A(t)\left(-v \frac{1}{\mu} \dot{R}(t)+\frac{1}{\mu}(\sigma+\tau) \dot{T}(t)-\frac{1}{\mu} k_{T} \dot{T}\right)-k_{A} e_{A}\right)$

olarak tanımlanır, (20)' de yerine yazılırsa

$\dot{L}_{A}=-k_{A} e_{A}^{2}$

olur. Böylece, $I(t) \rightarrow I^{d}(t) \Rightarrow e_{A} \rightarrow 0$ sonucu eşitlik (22)'den kolayca görülebilir. Bir sonraki ve son adımda ise,

$e_{I}=I(t)-I^{d}(t)$

hatasını kontrol etmek için, gerçek kontrol parametreleri $\alpha, \beta$ kullanılacaktır.

\section{3. $\alpha, \beta$ ile e $e_{I}$ 'nın kontrolü}

Bu bölümde ise, gerçek kontrol parametreli, $\alpha, \beta$, (23) ü kontrol etmek için tasarlanmaktadır. Bunun için, ilk olarak

$$
L_{I}=\frac{1}{2} e_{I}^{2}
$$

tanımlanır ve türevi alınarak

$$
\dot{L}_{I}=e_{I} \dot{e}_{I}=e_{I}\left(\dot{I}-\dot{I}^{d}\right)
$$

elde edilir. Daha sonra, $\Gamma=\frac{(\theta+\mu+\kappa)}{\zeta}$ olarak tanımlanır, eşitlik (21)'in türevi alınır,

$$
\begin{aligned}
& \dot{I}^{d}(t)=\Gamma \dot{A}(t)\left(-v \frac{1}{\mu} \dot{R}(t)+\frac{1}{\mu}(\sigma+\tau) \dot{T}(t)-\frac{1}{\mu} k_{T} \dot{T}\right) \\
& +\Gamma A(t)\left(-v \frac{1}{\mu} \ddot{R}(t)+\frac{1}{\mu}(\sigma+\tau) \ddot{T}(t)-\frac{1}{\mu} k_{T} \ddot{T}\right)-\frac{1}{\zeta} k_{A}\left(\dot{A}-\dot{A}^{d}\right)
\end{aligned}
$$

olarak bulunur ve burada, $\ddot{R}(t), \ddot{T}(t)$ sırasıyla eşitlik (5), (6) nın türevleri alınarak bulunur. Daha sonra, (26) ve (2) eşitlik (25)'de yerine yazılınca 


$$
\dot{L}_{I}=e_{I}\left(\begin{array}{l}
S(t)(\alpha I(t)+\beta D(t)+\gamma A(t)+\delta R(t))-(\varepsilon+\zeta+\lambda) I(t) \\
-\Gamma \dot{A}(t)\left(-v \frac{1}{\mu} \dot{R}(t)+\frac{1}{\mu}(\sigma+\tau) \dot{T}(t)-\frac{1}{\mu} k_{T} \dot{T}\right) \\
-\Gamma A(t)\left(-v \frac{1}{\mu} \ddot{R}(t)+\frac{1}{\mu}(\sigma+\tau) \ddot{T}(t)-\frac{1}{\mu} k_{T} \ddot{T}\right)+\frac{1}{\zeta} k_{A}\left(\dot{A}-\dot{A}^{d}\right)
\end{array}\right)
$$

olarak bulunur. Eşitlik (27) kullanılarak, iki farklı kontrolcü aşağıdaki gibi verilmiştir

$$
\begin{aligned}
& \alpha=\frac{1}{I(t) S(t)}\left(-\beta D(t)-\gamma A(t)-\delta R(t)-k_{I} e_{I}\right) \\
& -\frac{1}{I(t)}\left(\begin{array}{l}
\left.-(\varepsilon+\zeta+\lambda) I(t)+\Gamma \dot{A}(t)\left(-v \frac{1}{\mu} \dot{R}(t)+\frac{1}{\mu}(\sigma+\tau) \dot{T}(t)-\frac{1}{\mu} k_{T} \dot{T}\right)\right) \\
+\Gamma A(t)\left(-v \frac{1}{\mu} \ddot{R}(t)+\frac{1}{\mu}(\sigma+\tau) \ddot{T}(t)-\frac{1}{\mu} k_{T} \ddot{T}\right)-\frac{1}{\zeta} k_{A}\left(\dot{A}-\dot{A}^{d}\right)
\end{array}\right) \\
& \beta=\frac{1}{D(t) S(t)}\left(-\alpha I(t)-\gamma A(t)-\delta R(t)-k_{I} e_{I}\right) \\
& -\frac{1}{D(t)}\left(\begin{array}{l}
-(\varepsilon+\zeta+\lambda) I(t)+\Gamma \dot{A}(t)\left(-v \frac{1}{\mu} \dot{R}(t)+\frac{1}{\mu}(\sigma+\tau) \dot{T}(t)-\frac{1}{\mu} k_{T} \dot{T}\right) \\
+\Gamma A(t)\left(-v \frac{1}{\mu} \ddot{R}(t)+\frac{1}{\mu}(\sigma+\tau) \ddot{T}(t)-\frac{1}{\mu} k_{T} \ddot{T}\right)-\frac{1}{\zeta} k_{A}\left(\dot{A}-\dot{A}^{d}\right)
\end{array}\right)
\end{aligned}
$$

, burada $k_{I}>0$ kontrol kazancıdır. Eşitlik (28) veya (29), eşitlik (27)'de yerine yazılırsa,

$$
\dot{L}_{I}=-k_{I} e_{I}^{2}
$$

elde edilir. Yukarıda verilen kontrolcülerden, (28) veya (29), biri tercih edilecektir. Tercih edilen kontrolcü dinamik olarak hesaplanırken, diğer kontrol parametresi sabit kabul edilecektir.

Not: $\mathrm{Bu}$ çalışmada, yayılım parametrelerinden sadece iki tanesi için kontrolcü tasarımı yapılmıştır, (28), (29). Diğer iki yayılım parametreleri $\gamma, \delta$ için de, ilk adımları aynı kalmak suretiyle, son adımda kontrolcü tasarımı yapilabilir.

\subsection{Normalize edilmiş kontrolcü hesaplanması}

$\mathrm{Bu}$ bölümde, eşitlik (28) ve (29) da verilen kontrolcüler normalleştirilmiştir. Bunun sebebi, gerçek salgın yönetiminde, başlangıç değerleri $\alpha=0.57, \beta=0.011$ olarak verilen kontrol parametreleri, kontrol edildiğinde

$0 \leq \alpha<0.57,0 \leq \beta<0.011$, aralığında değer alacaktır. $\mathrm{Bu}$ yüzden, kontrol parametrelerinin başlangıç değerleri $\alpha_{b}=0.57, \beta_{b}=0.011$, olarak tanımlanmış ve normalleştirilmiş geri adımlamalı kontrolcüler aşağıdaki gibi verilmiştir

$$
\begin{aligned}
& \alpha(t)>\alpha_{b} \Rightarrow \alpha(t)=\alpha_{b}, \\
& \beta(t)>\beta_{b} \Rightarrow \beta(t)=\beta_{b}, \\
& \alpha(t) \leq \alpha_{b} \Rightarrow \alpha(t)=\alpha_{b}-\alpha_{b}\left(1-e^{\left(\alpha-\alpha_{b}\right) / c}\right), \\
& \beta(t) \leq \beta_{b} \Rightarrow \beta(t)=\beta_{b}-\beta_{b}\left(1-e^{\left(\beta-\beta_{b}\right) / c}\right) .
\end{aligned}
$$

Eşitlik (32)'de, $c>0$ fonksiyonun 0'a yakınsama hızını vermektedir ve kullanıcı tarafindan belirlenebilmektedir. Böylece, kontrol parametreleri (28) ve (29), (32)'de ki gibi normalleştirildiğinde, (31) garanti edildiği görülmektedir.

Sadece bir yayılım parametresinin değeri, geri besleme ile hesaplandiktan (28) ve normalleştirildikten (32) sonra, kalan üç yay1lım parametresi, hesaplanan parametre ile aynı oranda 
değiştiği varsayılarak aşağıdaki gibi hesaplanmıştır. Aşağıdaki hesaplamada, $\alpha$ 'nın geri besleme ile hesaplandığ 1 varsayılmış ve diğer parametrelerin, referans yayin (Giordano vd., 2020)'da verilen değerleriyle orantılı olarak $\alpha$ 'ya bağlı değer aldığg düşünülmüştür.

$\beta(t)=\alpha(t) \frac{0.011}{0.57}, \gamma(t)=\alpha(t) \frac{0.456}{0.57}, \delta(t)=\alpha(t) \frac{0.011}{0.57}$

Sonraki bölümde, kontrol stratejimiz benzetim çalışması yardımıyla denemiştir ve sonuçlar kontrolcünün hasta sayısını istenen sayının altında tuttuğu gözlemlenmiştir.

\section{Benzetim sonuçları ve tartışma}

$\mathrm{Bu}$ bölümde, covid-19 salgının yayılım denklemleri (1)-(8)'i kontrol etmek için tanımlanan kontrolcülerden, ilkinin, (28), salgının yayılımda belirlenen hasta sayısının aşılmadığını gösterilmektedir. $\mathrm{Bu}$ bağlamda, iki aşamalı bir yaklaşım verilmiştir. Birinci kısımda, İtalya için
(Giordano vd., 2020)'de verilen başlangıç katsayıları kullanmıştır ve hiçbir kontrol olmadığında salgın sonucunda tablo nasıl olacaktı sorusunun cevabı verilmiştir. İkinci kısımda ise, bizim öne sürdüğümüz geri adımlamalı kontrolcü nün uygulanması sonucunda tablo verilmiştir.

\subsection{Kontrolsüz Yayılım Sonuçları}

İtalya'da salgının başlangıcında aşağıdaki yayılım katsayıların geçerli olduğu (Giordano vd., 2020) 'de verilmiştir.

$$
\begin{aligned}
& \alpha=0.57, \beta=0.011, \gamma=0.456, \delta=0.011, \varepsilon=0.171, \theta=0.371, \zeta=0.125, \eta=0.125 \\
& \mu=0.017, v=0.027, \tau=0.01, \lambda=0.034, \rho=0.034, \kappa=0.017, \xi=0.017, \sigma=0.017
\end{aligned}
$$
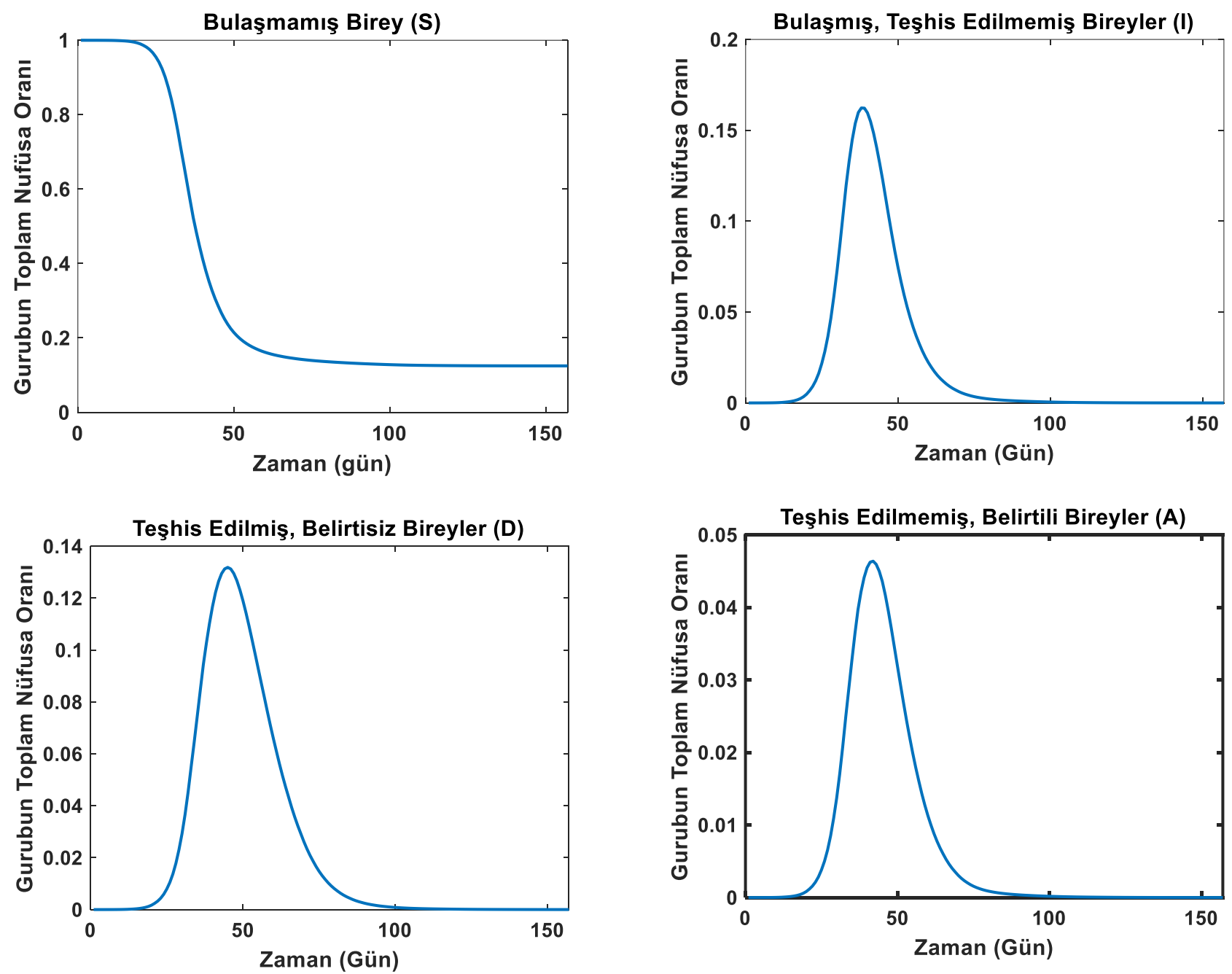

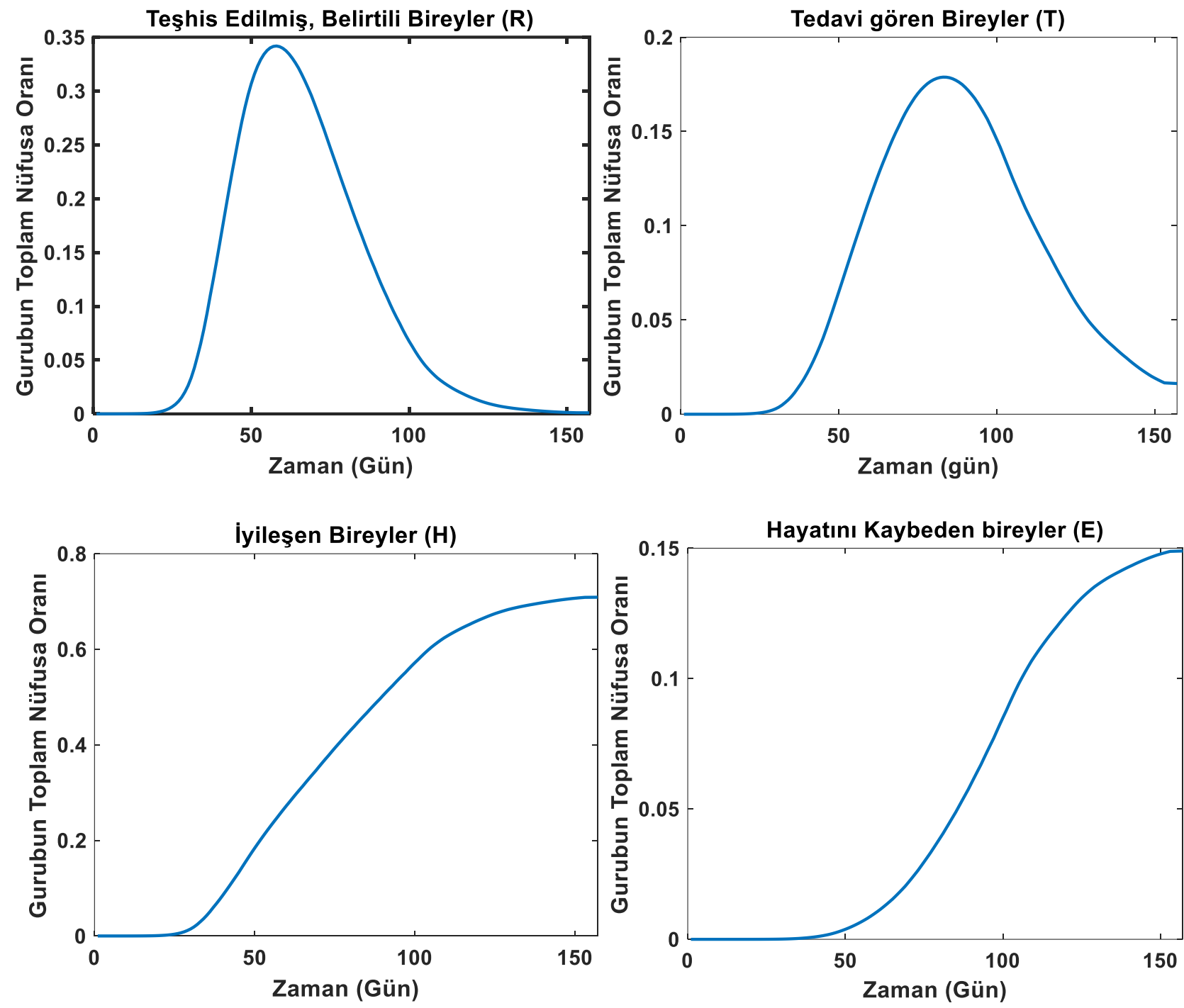

Şekil 2. (Giordano vd., 2020)'de verilen başlangıç parametreleri ile (kontrolsüz yayılım) salgının sonuçta hangi boyuta ulaşacağını gösteren grafikler.

Şekil 2' de gösterildiği üzere, hastaneye yatan hasta say1s1 $(\mathrm{T})$, toplam nüfusun $\% 18$ i oluyor tepe noktasinda. Bu da İtalya'da 10.800 .000 hasta anlamına geliyor ki bu büyüklükte hastane kapasitesinin olmas1 mümkün değildir. $\mathrm{Bu}$ sebepten, bir sonraki bölümde, azami hasta sayısını aşmayacak şekilde kontrolü ile ilgili benzetim sonuçları verilmiştir.

\subsection{Kontrollü yayılım sonuçları}

Bu bölümde, $\alpha$ parametresinin (28) eşitliği ile dinamik olarak hesaplanı, (32) ile normalleştirilmiş hali, sistem dinamiğine uygulandığ 1 durumda sonuçlar verilmiştir. $\beta(t), \gamma(t), \delta(t)$ parametreleri $\alpha(t)$ ' ye bağl olarak (33) den hesaplanmıştır. Azami hasta yatak say1s1, $\quad T^{\max }=0.0012 * 60000000=72000$ olarak alınmıştır ve diğer yayılım parametrelerinin değişmediği varsayılmıştır.

$$
\begin{aligned}
& \theta=0.371, \zeta=0.125, \eta=0.125 \mu=0.017, \nu=0.027, \tau=0.01, \\
& \lambda=0.034, \rho=0.034, \kappa=0.017, \xi=0.017, \sigma=0.017
\end{aligned}
$$



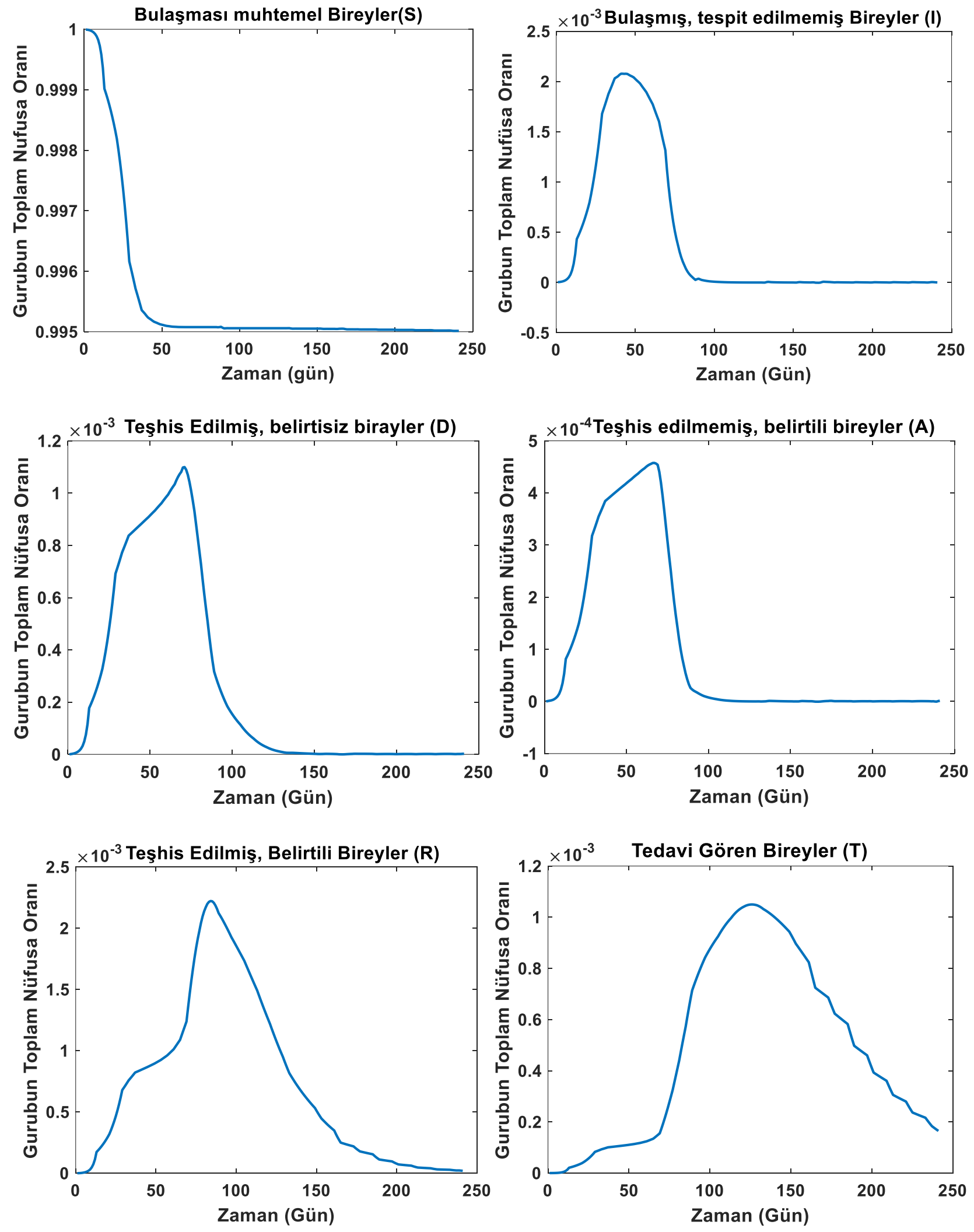

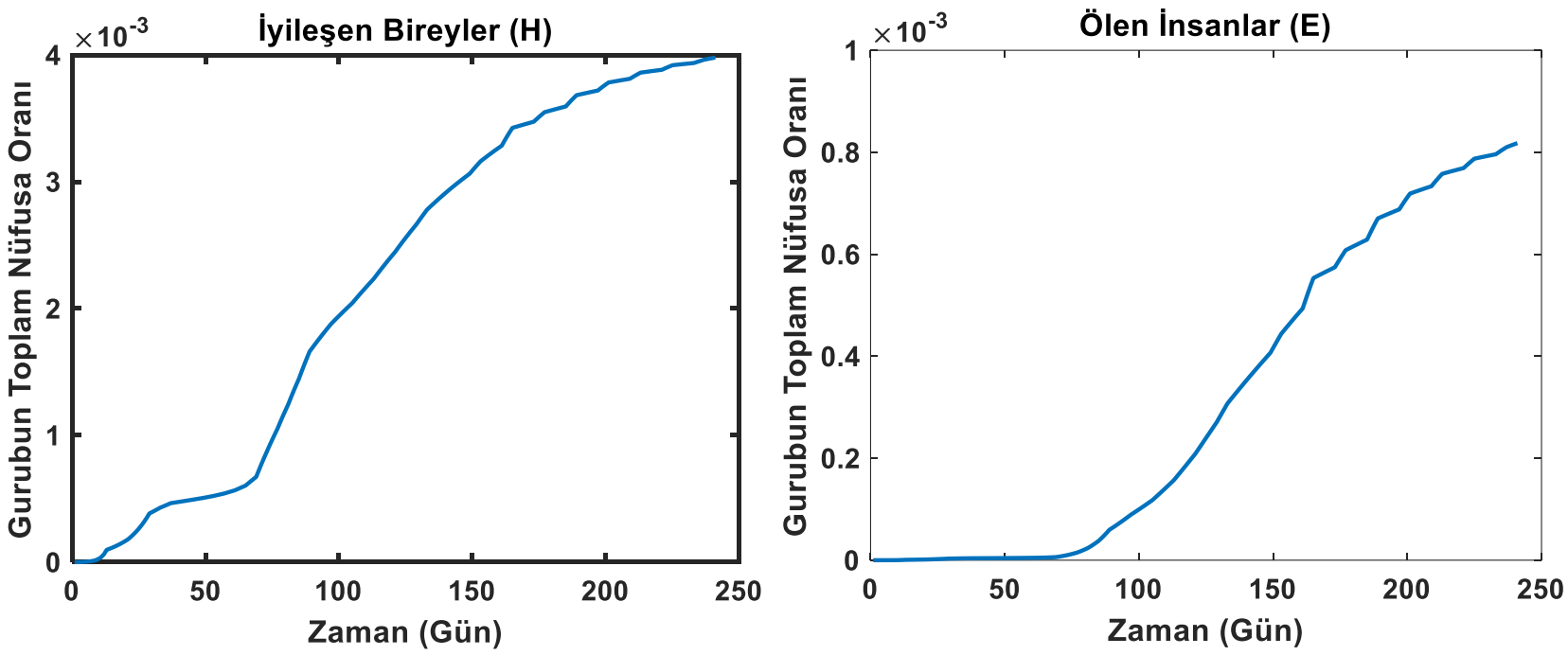

Şekil 3. (Giordano vd., 2020)'de verilen başlangıç parametreleri (35) ve dinamik $\alpha$ (kontrollü yayılım) durumunda salgının ne duruma ulaşacağını gösterir grafikler.

Şekil 3'deki bütün grafiklerin ilk 10 günlük kısmı incelendiğinde, kontrolsüz bir yayılım göze çarpmaktadır. Örneğin, bulaşmamış bireyler (S) grafiğinde üstel bir iniş varken ilk 10 gün, kontrollü yayılıma geçildiği andan itibaren, düşüş hız azalmış ve yataya yakın bir seyir izlemeye başlamıştır. İlk günlerdeki hızlı yayılmanın sebebini Şekil 4'den de gözlemlemek mümkündür. Geri adımlamalı kontrolcü yöntemi ile hesaplanmış $\alpha$ katsayısının, ilk 10 günlük süreçte kontrolsüz yayılımdaki değerine, 0.57 'ye, ve diğer parametrelerin de kontrolsüz yayılımdaki değerlerine eşit olduğu görülmektedir.
Bu çalışmada, kontrolcü tasarımında, tüm durum değişkenlerinin, $S, I, D, A, R, T, H, E$ temin edilebilir olduğu varsayılmıştır. Halbuki, gerçek hayatta, özellikle tespit edilememiş bireylerin gerçek sayısı elde edilemez. Bu durumda, geri beslemeli kontrolcü tasarlarken, gözlemci tabanlı kontrol yaklaşımından yararlanılabilir. Sistem modeli kullanılarak, ölçülebilir durum değişkenleri üzerinden, örneğin $T, E$ gibi, ölçülemeyen durum değişkenleri kestirilebilir. Bu problem, bir sonraki adımda araştırmacıların dikkate almasını önereceğimiz bir konudur.
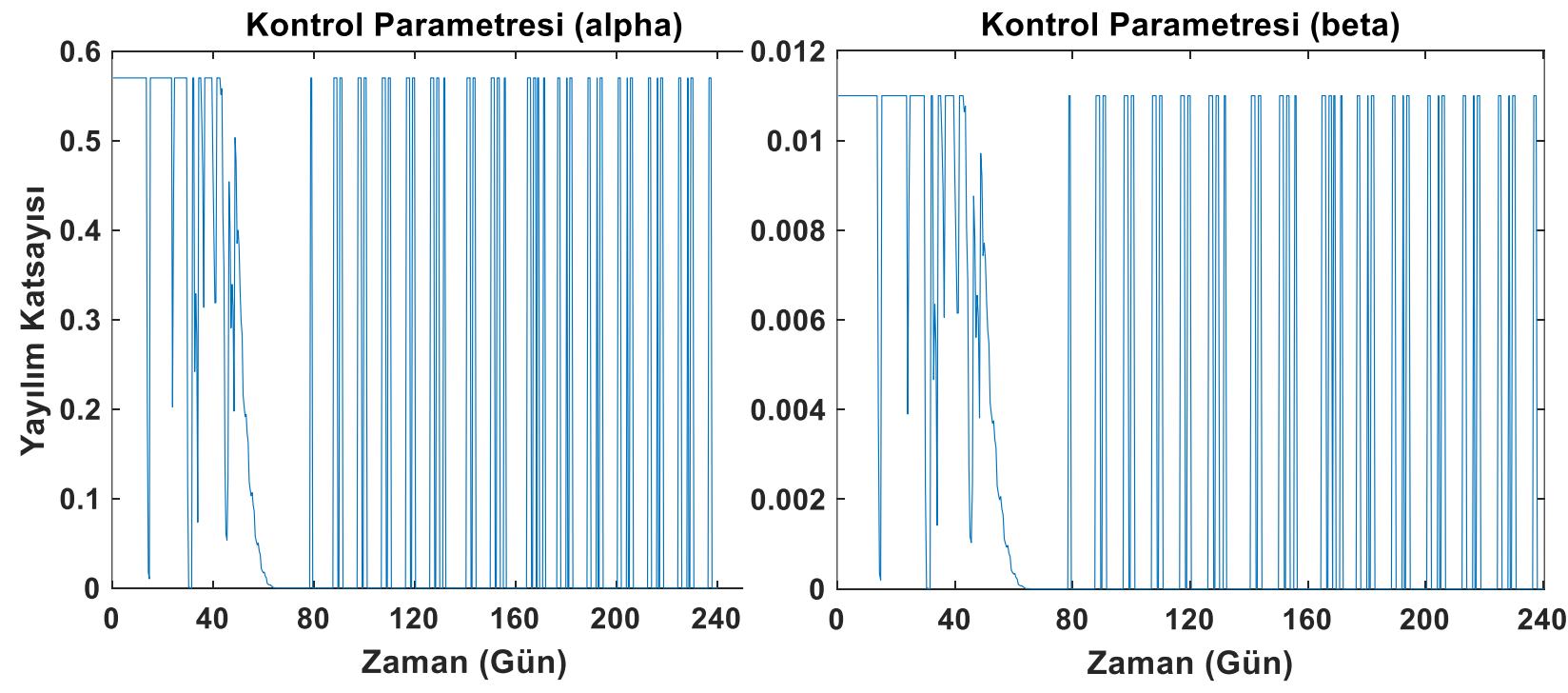

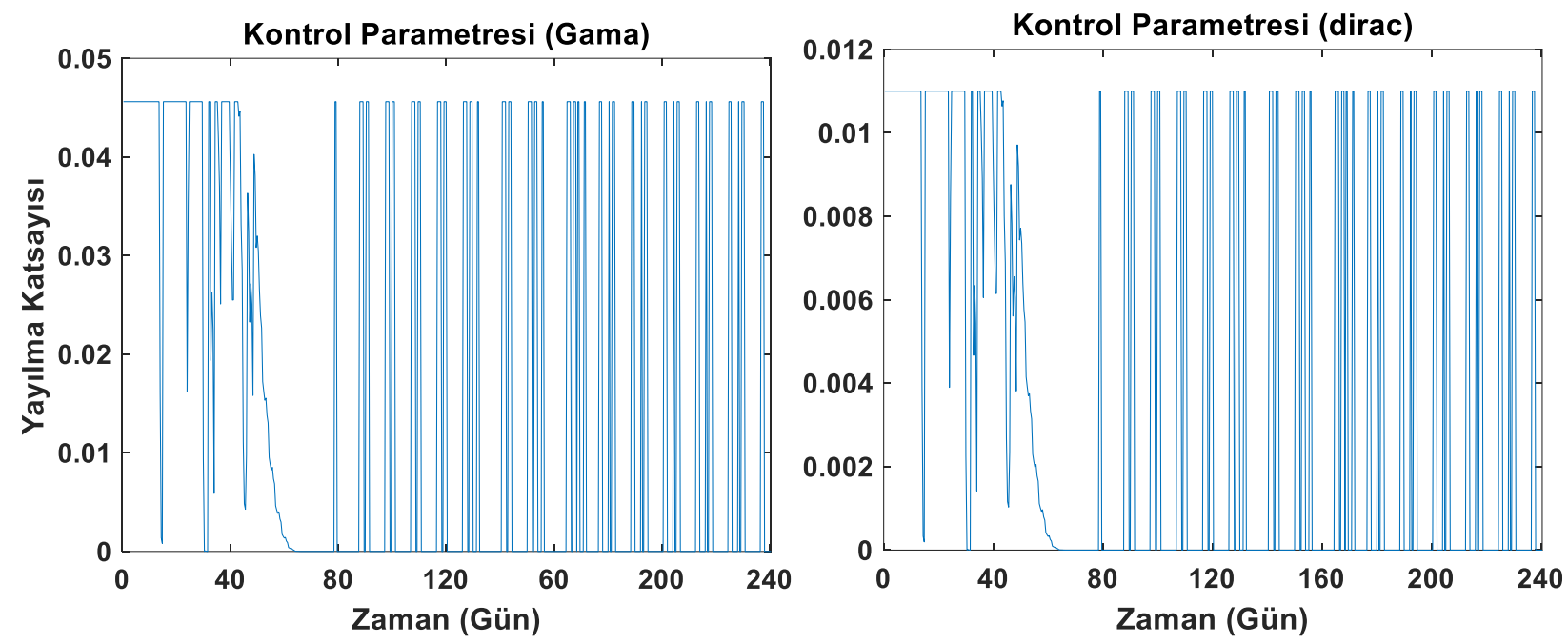

Şekil 4. Kontrol parametrelerinin, $\alpha, \beta, \gamma, \delta$ 'nın zamanla değişimi.

Şekil 3'de verildiği üzere, hastanede yatan hasta sayıs1 (T), toplam nüfusa oranla $1.2 * 10^{-3}$ 'ün altında kalmış ve gerekli yatak sayısı tepe noktasında bile 62.400 civarında kalmıştır. Şekil 4 ise, kontrol parametreleri $\alpha, \beta, \gamma, \delta$ 'nın zamanla değişimini göstermektedir. İlk 10 günlük süreçte, parametrenin değeri kontrolsüz yayılımdaki değerlerinde sabit kalmıştır. Bunun fiziksel anlamı, kontrol algoritması temas k1sitlamasina gereksinim duymamıştır. Daha sonraki 20 günlük süreçte ise, belirli günlerde parametre 0'a yakın değerlere inerek, sosyal tecrit olması gereken günleri göstermektedir. Kontrol parametresi, 45. gün ile 70. gün arasinda ise, kademeli olarak 0'a inmektedir. Bunun fiziksel anlamı, her geçen gün sosyal hayatın içerisinde bazı faaliyetlerin yasaklanmasidır. 70. günden sonra ise kontrol parametresi bazı günler 0'da sabit kalarak, topyekûn tecrit gerektiğini dikte ederken, bazı günler daha esnek davranılabileceğini söylemektedir.

\section{Kaynaklar}

Barbarossa, M. V., Fuhrmann, J., Heidecke, J., Varma, H. V., Castelletti, N., Meinke, J. H., Krieg, S. and Lippert, T. (2020). A first study on the impact of current and future control measures on the spread of COVID-19 in Germany. medRxiv preprint. https://doi.org/10.1101/2020.04.08.20056630.

Bin, M., Cheung, P., Crisostomi, E., Ferraro, P., Myant, C., Parisini, T. and Shorten R. (2020). On fast multi-shot epidemic interventions for post lockdown mitigation: Implications for simple COVID-19 models. arXiv:2003.09930.

Casella F. (2020). Can the COVID-19 epidemic be managed on the basis of daily data? IEEE
Control Systems Letters, 5(3), 1079-1084. https://doi.org/10.1109/LCSYS.2020.3009912

Casella F. (2021). Can the COVID-19 Epidemic be controlled on the basis of daily test reports? IEEE Control Systems Letters. 5(3),1079-1084. https://doi.org/10.1109/LCSYS.2020.3009912.

Dehning, J., Zierenberg, J., Spitzner, F. P., Wibral, M., Neto, J. P., Wilczek, M. and Priesemann, V. (2020). Inferring COVID-19 spreading rates and potential change points for case number forecasts. $\quad$ Science $369(6500)$. https://doi.org/10.1126/science.abb9789

German, R., Djanatliev, A., Maile, L., Bazan, P. and Hackstein, H. (2020). Modeling exit strategies from COVID-19 lockdown with a focus on antibody tests. medRxiv preprint. https://doi.org/10.1101/2020.04.14.20063750.

Giordano, G., Blanchini, F., Bruno, R., Colaneri, P., Filippo, A. D., Matteo, A. D. and Colaneri, M. (2020). Modelling the COVID-19 epidemic and implementation of population-wide interventions in Italy. Nature Medicine.26, 855-860. https://doi.org/10.1038/s41591-020-0883-7

Guzey, H. M., Xu, H. and Sarangapani, J. (2016). Neural network-based finite horizon optimal adaptive consensus control of mobile robot formations. Optimal Control Applications and Methods $37(5)$, 1014-1034. https://doi.org/10.1002/oca.2222

Guzey, H. M., Vignesh, N., Jagannathan, S., Dierks, T. and Acar, L. (2017). Distributed consensusbased event-triggered approximate control of nonholonomic mobile robot formations, American Control Conference (ACC), Seattle, WA, 3194-3199. https://doi.org/10.23919/ACC.2017.7963439 
Guzey, H. M., Dierks, T. and Jagannathan, S. (2019). Modified consensus-based output feedback control of quadrotor UAV formations using neural networks. Journal of Intelligent \& Robotic Systems 94, 283-300. https://doi.org/10.1007/s10846-018-0961-y

Kissler, S., Tedijanto, C., Lipsitch, M. and Grad, Y. H. (2020). Social distancing strategies for curbing the COVID-19 epidemic, medRxiv preprint. https://doi.org/10.1101/2020.03.22.20041079.

Lauro, F. D., Kiss, I. Z., Rus, D. and Santina, C. D. (2021). Covid-19 and flattening the curve: A feedback control perspective. IEEE Control Systems Letters 5(4), 1435-1440. https://doi.org/10.1109/LCSYS.2020.3039322.
Maharaj, S. and Kleczkowski, A. (2012). Controlling epidemic spread by social distancing: Do it well or not at all. BMC Public Health 12 (679), 1-16. https://doi.org/10.1186/1471-2458-12-679

Maier, B. F. and Brockmann, D. (2020). Effective containment explains subexponential growth in recent confirmed COVID-19 cases in China. Science 368(6492) 742-746. https://doi.org/10.1126/science.abb4557.

Tsay, C., Lejarza, F., Stadtherr, M. A. and Baldea, M. (2020). Modeling, state estimation, and optimal control for the US COVID-19 outbreak. Scientific Reports 10, 10711. https://doi.org/10.1038/s41598-020 